\title{
Comparative study of the relationship between multi-frequency impedance and body water compartments in two European populations
}

\author{
BY ANNA TAGLIABUE AND HELLAS CENA \\ Department of Human Nutrition, University of Pavia, Via Bassi 21, 27100 Pavia, Italy \\ AND PAUL DEURENBERG \\ Department of Human Nutrition, Wageningen Agricultural University, Bomenweg 2, \\ 6703 HD Wageningen, The Netherlands
}

(Received 14 July 1994 - Revised 8 March 1995 - Accepted 3 May 1995)

\begin{abstract}
To investigate possible differences in the relationship between multi-frequency impedance and bodywater compartments (total body water (TBW) and extracellular water (ECW)) measured by dilution techniques in two European populations, we studied forty Italian (twenty male and twenty female) and forty-three Dutch (twenty-three male and twenty female) healthy subjects aged 19-41 years. The main differences in body build between the two groups were height, trunk length and the two ratios TBW/height and ECW/height. Population-specific prediction formulas for ECW (at $1 \mathrm{kHz}$ ) and TBW (at $100 \mathrm{kHz}$ ) were developed. The prediction errors for ECW and TBW were about 0.6 and $1.5 \mathrm{~kg}$ respectively, (CV 4\%) in both groups. Cross-validation analysis showed no significant error in the prediction of TBW but a slight error (range -4.9 to $+2.8 \%$ ) in the ECW prediction. The biases in both TBW and ECW were correlated with ECW/TBW $(r-0.44, P<0.0005$ and $r+0.52, P<0.0005$ respectively) in the two groups; the biases in ECW were also related to ECW/height $(r 0.51, P<0.001)$, TBW/height $(r 0.25, P<0.05)$, trunk length $(r 0.36, P<0.001)$ and $Z_{1} / Z_{100}(r 0.32, P<0.01)$. In conclusion, the water distribution between the extra- and intracellular compartments emerged in the present study as the major cause of error in the prediction of body water, and in particular of ECW from impedance measurements with a population-specific equation. Moreover, body build, expressed as TBW/height and ECW/height, had an impact on the bias.
\end{abstract}

Body composition: Total body water: Multi-frequency bioimpedance

In the average adult individual $50-60 \%$ of body weight is water; the intracellular component of body water accounts for about $\mathbf{4 0} \%$ of body weight and the extracellular component for about $20 \%$. Approximately $25 \%$ of the extracellular component is in the vascular system (plasma) and $75 \%$ outside the blood vessels (interstitial fluid). In general, the extracellular water:total body water ratio (ECW/TBW) is higher in females and children. In healthy adults ECW/TBW increases with age from an average of 0.42 at age 30 years to 0.48 at 80 years (Forbes, 1987).

Recent studies have used multi-frequency impedance measurements to predict ECW at low frequency and TBW at high frequency, with a prediction error of about $1 \mathrm{~kg}$ for ECW and $2 \mathrm{~kg}$ for TBW (Segal et al. 1991; Deurenberg, 1995). The relationship between impedance and body water depends on body-water distribution, owing to differences in specific resistivity of extra- and intracellular water (Deurenberg et al. 1989). Moreover, as impedance is much higher in the extremities than in the trunk (Baumgartner et al. 1989; 
Fuller \& Elia, 1989), differences in body build, e.g. differences in the trunk length: extremity length ratio, may influence the validity of the measurements. Thus a prediction formula developed in one population may yield different results for predicted, as compared with measured, body composition when used in another population. Therefore, most authors recommend the use of population-specific prediction formulas, e.g. specific for age, sex and ethnicity, for the prediction of body water from bio-electrical impedance.

The aim of the present investigation was to study the relationship between impedance and body-water compartments in two European populations, and to relate a possible bias to differences in body build.

\section{MATERIALS AND METHODS}

Subjects

Two study groups, one in Northern Italy (Pavia) and one in The Netherlands (Wageningen), participated in the study. The groups were composed of adult healthy volunteers of both sexes; some physical and body-build characteristics are presented in Tables 1 and 2 . All subjects gave their informed consent to the procedures described and the study was approved by the Ethical Committees of the Universities of Pavia and Wageningen.

\section{Experimental design}

In each study centre the measurement procedures followed the same protocol. All measurements were performed in the morning in the fasting state. After voiding, the subjects took a tracer dose of ${ }^{2} \mathrm{H}_{2} \mathrm{O}$ and $\mathrm{KBr}$ orally. Immediately after that, body impedance $\left(Z_{\mathrm{f}}\right)$ was measured on the left side of the body, using self-adhesive ECG electrodes with a surface area of about $500 \mathrm{~mm}^{2}$ (Littman $2325 \mathrm{VP}, 3 \mathrm{M}$, St Paul, MN, USA) and a multi-frequency impedance analyser (Human Im Scan, Dietosystem, Milano, Italy) along the entire frequency range from $300 \mathrm{~Hz}$ to $100 \mathrm{kHz}$. Oniy the values for 1,5 , 50 and $100 \mathrm{kHz}$ are used in the statistical analysis. Then body weight and height were measured. Impedance index was calculated as height ${ }^{2} / \mathrm{Z}_{\mathrm{f}}\left(\mathrm{m}^{2} / \Omega\right)$. BMI was calculated as weight $(\mathrm{kg}) /$ height $^{2}\left(\mathrm{~m}^{2}\right)$. Finally, several anthropometric variables were measured. The subjects remained in the fasting state (without eating or drinking) until $2.5 \mathrm{~h}$ after the intake of the ${ }^{2} \mathrm{H}_{2} \mathrm{O}-\mathrm{KBr}$ dose. Then a blood sample was taken, and the plasma was stored at $-80^{\circ}$ until analysed.

\section{Anthropometric measurements}

Body height was measured to the nearest $1 \mathrm{~mm}$ with a wall-mounted stadiometer and weight (in light underwear) was measured to the nearest $0 \cdot 1 \mathrm{~kg}$ with a digital scale. Leg length was measured as trochanter height, which is the height from the floor to the great trochanter. It was measured with a microtoise with the subject standing upright. Shoulder height was measured in the standing position with the microtoise placed on the tip of the collar bone. Trunk length was calculated as the difference between shoulder height and trochanter height. Arm length was measured from the tip of the acromion to the wrist. All heights and lengths were measured to the nearest $1 \mathrm{~mm}$ on the left side. Mid-arm circumference (left side) was measured at the midpoint between acromion and olecranon. Waist circumference was measured midway between the lower rib margin and the iliac crest. Hip circumference was measured at the level of the great trochanters. The upper thigh circumference (left side) was measured midway between the iliac crest and the patella. The 
Table 1. Characteristics of the study population

(Mean values and standard deviations)

\begin{tabular}{|c|c|c|c|c|c|c|c|c|}
\hline & \multicolumn{4}{|c|}{ Males } & \multicolumn{4}{|c|}{ Females } \\
\hline & \multicolumn{2}{|c|}{ Italy } & \multicolumn{2}{|c|}{ The Netherlands } & \multicolumn{2}{|c|}{ Italy } & \multicolumn{2}{|c|}{ The Netherlands } \\
\hline & Mean & SD & Mean & SD & Mean & SD & Mean & SD \\
\hline$n$ & \multicolumn{2}{|c|}{20} & \multicolumn{2}{|c|}{23} & \multicolumn{2}{|c|}{20} & \multicolumn{2}{|c|}{20} \\
\hline Age (years) & $21 \cdot 7$ & 1.5 & $31 \cdot 0^{*}$ & $3 \cdot 5$ & $22 \cdot 2$ & $2 \cdot 4$ & $32 \cdot 7^{*}$ & 5.5 \\
\hline Weight (kg) & $72 \cdot 7$ & $8 \cdot 6$ & $77 \cdot 4$ & $11 \cdot 3$ & $56 \cdot 6$ & $5 \cdot 3$ & $71 \cdot 1 *$ & $15 \cdot 3$ \\
\hline Height (m) & $1 \cdot 77$ & 0.06 & $1 \cdot 84^{*}$ & 0.07 & 1.63 & 0.06 & $1.67^{*}$ & 0.03 \\
\hline BMI $\left(\mathrm{kg} / \mathrm{m}^{2}\right)$ & $23 \cdot 1$ & $2 \cdot 8$ & $22 \cdot 9$ & $2 \cdot 7$ & $21 \cdot 2$ & $1 \cdot 7$ & $25 \cdot 5^{*}$ & $6 \cdot 2$ \\
\hline Body fat $(\%) \dagger$ & $24 \cdot 3$ & $5 \cdot 9$ & $17 \cdot 4^{*}$ & $4 \cdot 6$ & $26 \cdot 3$ & $4 \cdot 8$ & $30.8^{*}$ & 6.8 \\
\hline TBW (kg) & $42 \cdot 2$ & $3 \cdot 6$ & $44 \cdot 8 *$ & $4 \cdot 6$ & $29 \cdot 0$ & $2 \cdot 9$ & $33 \cdot 7^{*}$ & $3 \cdot 8$ \\
\hline ECW (kg) & $16 \cdot 3$ & $1 \cdot 2$ & $17 \cdot 7^{*}$ & $2 \cdot 0$ & 11.8 & $1 \cdot 1$ & $14 \cdot 4^{*}$ & 1.6 \\
\hline ECW/TBW & 0.39 & $0 \cdot 02$ & $0 \cdot 39$ & 0.01 & 0.41 & 0.03 & $0.43^{*}$ & 0.02 \\
\hline $\begin{array}{l}\text { TBW/height } \\
(\mathrm{kg} / \mathrm{m})\end{array}$ & $23 \cdot 8$ & $1 \cdot 7$ & $24 \cdot 3$ & $2 \cdot 0$ & $17 \cdot 8$ & $1 \cdot 3$ & $20 \cdot 1^{*}$ & $2 \cdot 4$ \\
\hline $\begin{array}{c}\text { ECW/height } \\
(\mathrm{kg} / \mathrm{m})\end{array}$ & $9 \cdot 2$ & 0.6 & $9 \cdot 6$ & 0.9 & $7 \cdot 2$ & 0.5 & $8 \cdot 6^{*}$ & $1 \cdot 0$ \\
\hline $\mathrm{Z}_{1}(\Omega)$ & 595 & 51 & 594 & 56 & 709 & 52 & $649^{*}$ & 71 \\
\hline$Z_{5}(\Omega)$ & 580 & 50 & 570 & 55 & 694 & 52 & $625^{*}$ & 70 \\
\hline$Z_{50}(\Omega)$ & 501 & 44 & 486 & 46 & 615 & 49 & $546^{*}$ & 62 \\
\hline$Z_{100}(\Omega)$ & 467 & 42 & 451 & 43 & 575 & 45 & $510^{*}$ & 57 \\
\hline $\mathrm{Z}_{1} / \mathrm{Z}_{100}$ & $1 \cdot 28$ & 0.03 & $1 \cdot 31^{*}$ & 0.03 & $1 \cdot 23$ & 0.02 & $1 \cdot 27^{*}$ & 0.02 \\
\hline
\end{tabular}

TBW, total body water; ECW, extracellular water; $Z_{1}$, impedance at $1 \mathrm{kHz} ; Z_{5}$, impedance at $5 \mathrm{kHz} ; Z_{50}$, impedance at $50 \mathrm{kHz} ; \mathrm{Z}_{100}$, impedance at $100 \mathrm{kHz}$.

* Mean values were significantly different from those for Italian subjects of the same sex, $P<0 \cdot 05$.

$\dagger$ Estimated from skinfold thickness measurements.

circumference of the fibula (left) was measured at the level of the widest circumference. All circumferences were measured to the nearest $1 \mathrm{~mm}$ in the standing position with the subject leaning on his or her right leg, while the measurements were being taken on the left leg.

The thickness of four skinfolds was measured to the nearest $0.2 \mathrm{~mm}$ with Harpenden skinfold callipers according to the method described by Durnin \& Womersley (1974).

\section{Total body water and extracellular water}

TBW and ECW were determined using dilution techniques. The tracer dose was composed of an accurately-weighed dose of $15 \mathrm{~g}{ }^{2} \mathrm{H}_{2} \mathrm{O}$ and $900 \mathrm{mg}$ bromide $(1.34 \mathrm{~g} \mathrm{KBr})$. After sublimation of the plasma the deuterium concentration was determined in the sublimate using infrared spectroscopy (Lukaski \& Johnson, 1985). TBW was calculated using a correction factor of 0.95 for non-aqueous dilution (Forbes, 1987). Bromide in plasma was determined after ultrafiltration by HPLC (Miller \& Cappon, 1984). ECW was calculated using a correction factor of $\mathbf{0 . 9 0}$ for non-extracellular distribution and a correction factor of 0.95 for the Donnan effect (Forbes, 1987). The deuterium and bromide analyses were performed in the same laboratory (Wageningen). The technical precisions of the deuterium and bromide determinations were $1-2 \%$ and about $1 \%$ respectively. 
Table 2. Values for anthropometric variables in the study population

(Mean values and standard deviations)

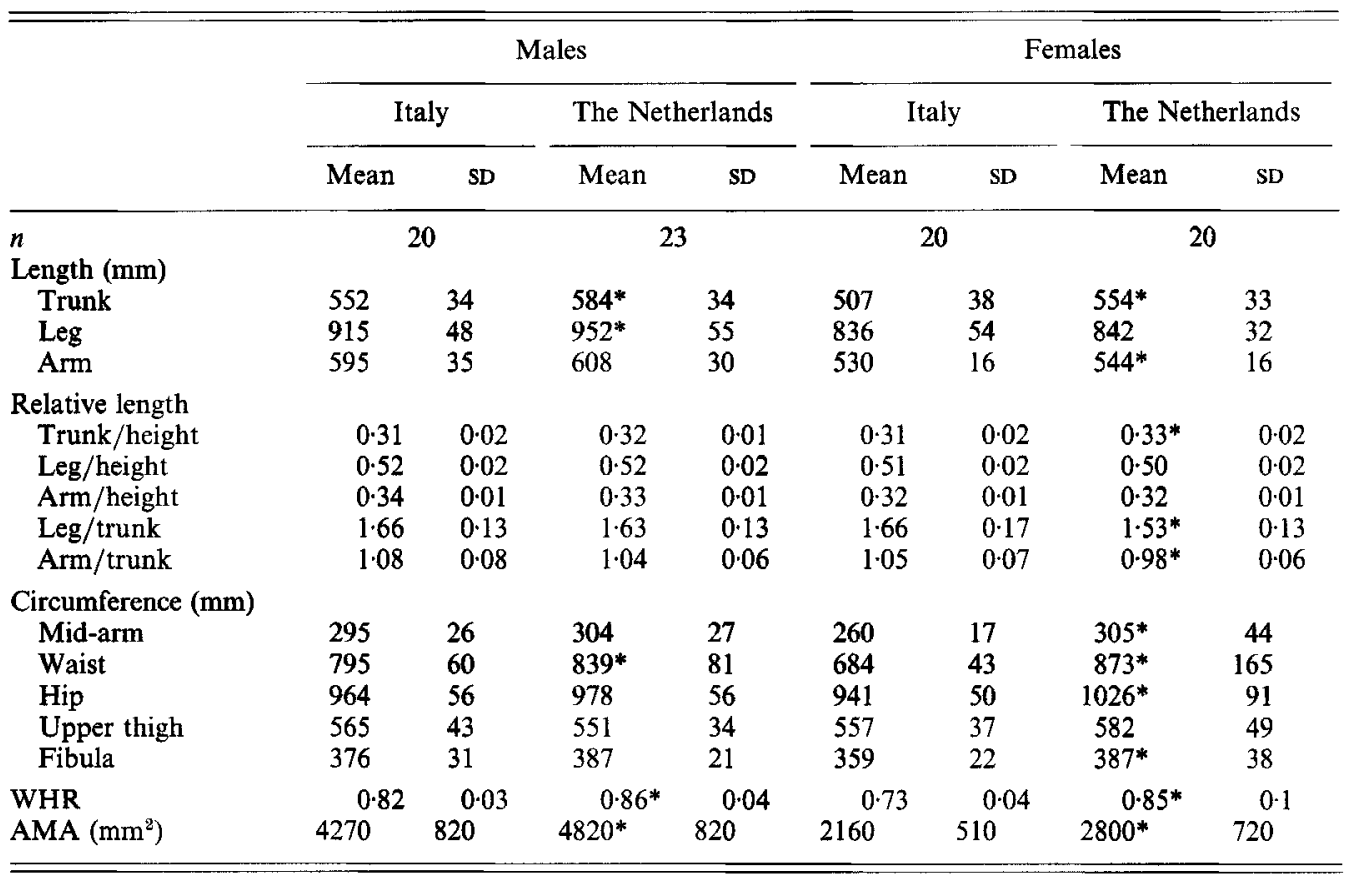

WHR, waist: hip ratio; AMA, arm muscle area.

* Mean values were significantly different from those for Italian subjects of the same sex, $P<0.05$.

\section{Statistical analysis}

Statistical analysis was carried out using the SPSS/PC software program (SPSS, 1990). Differences in variables between groups were tested for significance using ANOVA techniques. Stepwise multiple regression analysis was performed to study the relationship between measured water compartments and other variables. Sex and country were coded as dummy variables. Correlations are Pearson's product moment correlations or partial multiple correlations (Kleinbaum \& Kupper, 1978). Values are given as means and standard deviations. The level of two-tailed significance is 0.05.

\section{RESULTS}

Tables 1 and 2 show some characteristics of the study populations. The Dutch subjects (both males and females) were older and taller, and had higher TBW, ECW and $Z_{1} / Z_{100}$ values than the Italians. The relative (to height) water content (ECW/height and TBW/height) was similar in males but significantly different in females. The Dutch men had lower body fat (estimated from skinfold thickness) than the Italian men. The Dutch women were heavier, with higher BMI and body fat values than the Italian women; they also had higher ECW/TBW and lower impedance values. After correcting for age differences, the values of height, body fat, BMI and $Z_{1} / Z_{100}$ remained significantly different 
Table 3. Best-fitting equations for the prediction of total body water and extracellular water from impedance index and other variables in two population groups individually and together*

\begin{tabular}{|c|c|c|c|c|c|c|}
\hline \multirow[b]{2}{*}{ Variables } & \multicolumn{3}{|c|}{ Total body water } & \multicolumn{3}{|c|}{ Extracellular water } \\
\hline & I & NL & $\mathrm{I}+\mathrm{NL}$ & I & NL & $\mathrm{I}+\mathrm{NL}$ \\
\hline $\mathrm{H}^{2} / \mathrm{Z}_{100}\left(\mathrm{~cm}^{2} / \Omega\right)$ & $0 \cdot 26381$ & 0.34327 & $0 \cdot 30244$ & - & - & - \\
\hline $\mathrm{H}^{2} / \mathrm{Z}_{1}\left(\mathrm{~cm}^{2} / \Omega\right)$ & - & - & - & 0.11076 & $0 \cdot 18913$ & 0.18938 \\
\hline$Z_{1} / Z_{100}$ & - & - & - & - & - & $7 \cdot 11$ \\
\hline Weight (kg) & $0 \cdot 19805$ & $0 \cdot 13960$ & $0 \cdot 15355$ & 0.06573 & 0.06240 & 0.05983 \\
\hline Sext & $-4 \cdot 3$ & $-3 \cdot 3$ & $-4 \cdot 11$ & -1.7 & $-0 \cdot 3$ & - \\
\hline Intercept (kg) & $14 \cdot 08$ & $11 \cdot 42$ & $14 \cdot 34$ & $7 \cdot 32$ & $2 \cdot 3$ & $-7 \cdot 26$ \\
\hline $\mathbf{R}^{2}$ & 0.96 & 0.95 & 0.96 & 0.94 & 0.93 & 0.93 \\
\hline SEE (kg) & $1 \cdot 45$ & 1.59 & $1-51$ & 0.62 & 0.65 & 0.70 \\
\hline
\end{tabular}

I, Italy; $\mathrm{NL}$, The Netherlands; $\mathrm{H}$, height; $\mathrm{H}^{2} / \mathrm{Z}_{1}$, impedance index at $1 \mathrm{kHz} ; \mathrm{H}^{2} / \mathrm{Z}_{100}$, impedance index at $100 \mathrm{kHz}$; SEE, standard error of the estimate.

* $P$ value for entering in the regression model, 0.05 .

$\dagger$ Males, 1 ; females, 2.

between the two groups (height: $P<0.05$; BMI: $P<0.01$; body fat: $P<0.001 ; Z_{1} / Z_{100}$ $P<0.01$ ) in both sexes. The difference in height between the two groups is explained by the greater trunk and leg length of the Dutch men and by the greater trunk length (and trunk/height ratio) of the Dutch women (Table 2). After correcting for age differences between the two groups, the values of trunk length and arm/trunk ratio remained significantly different $(P<0.05)$.

The values for ECW and TBW were significantly correlated with the impedance index $\left(\mathrm{m}^{2} / \Omega\right)$ at $1,5,50$ and $100 \mathrm{kHz}(r 0.92-0.95, P<0.001)$ in both groups. As ECW and TBW are highly intercorrelated ( $r 0.96, P<0.001$ in both groups), the partial correlation of ECW with the impedance index after correction for the amount of TBW, and the partial correlation of TBW with the impedance index after correction for ECW were calculated at different frequencies. A significant relationship between $\mathrm{ECW}$ and height ${ }^{2} / \mathrm{Z}_{1}$ and height ${ }^{2} / Z_{5}$ persisted in the Dutch group after correction for TBW $(r 0.35, P<0.01$ for both frequencies). In the Italian group the partial correlation was not significant $(P=0.073$ and $P=0.052$ respectively), but showed the same trend as the Dutch group. The partial correlation of TBW after correction for ECW with impedance index at different frequencies increased with frequency. The highest correlation was found with height ${ }^{2} / Z_{100}$ in both the Italian $(r 0.52, P<0.001)$ and the Dutch groups $(r 0.58, P<0.001)$.

The ECW/TBW ratio was significantly correlated with the low/high impedance ratio $\left(Z_{1} / Z_{100}\right)$ in the Italians $(r-0.34, P<0.05)$ and in the Dutch $(r-0.68, P<0.001)$.

Table 3 gives the best fitting prediction formulas for ECW and TBW for the two groups, separately and in combination. The regression coefficients for the TBW and ECW equations did not differ significantly between the two groups. Cross-validation analysis showed no significant error in the prediction of TBW but a slight error in the ECW prediction (range -4.9 to $+2.8 \% ; P<0.0005$ ).

The biases of the predicted TBW and ECW were not correlated with the mean values of predicted and measured TBW or ECW. However, the biases in both TBW and ECW were correlated with the ECW/TBW ratio in the two groups (Fig. 1). The biases in ECW were also related to the ECW/height ratio $(r 0.51 ; P<0.001)$, TBW $/$ height $(r 0.25, P=0.022)$, 

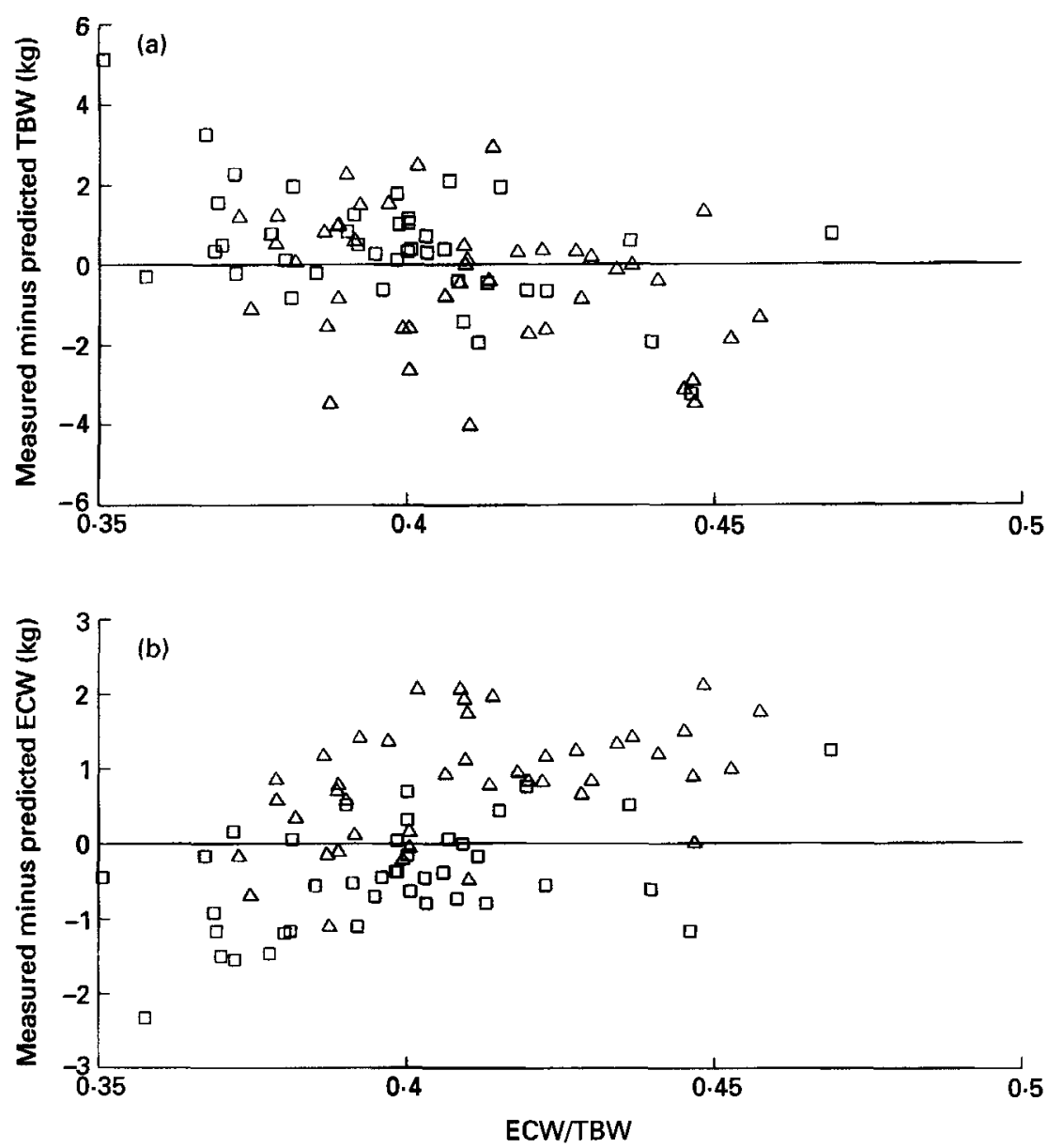

Fig. 1. Relationship between the extracellular water (ECW)/total body water (TBW) ratio and (a) measured - predicted TBW $(r-0.44, P<0.0005)$ and (b) measured - predicted ECW $(r 0.52, P<0.0005)$ with population-specific equations for subjects from Italy $(\square)$ and The Netherlands $(\triangle)$.

trunk length $(r 0.36 ; P=0.001)$, relative trunk length (trunk/height, $r 0.31, P=0.004$ ), relative (to trunk) arm and leg lengths (arm/trunk, $r-0.25, P=0.023 ; \mathrm{leg} /$ trunk, $r-0.23$, $P=0.033)$ and to the $Z_{1} / Z_{100}$ ratio $(r 0.32, P=0.003)$. Regression analysis with TBW as dependent variable and height $t^{2} / Z_{100}$, weight and sex as independent variables in the two combined groups (using the group as a dummy variable) showed no group effect in the observed relationship ( $P=0.31$; Table 3 ). ECW prediction in the two combined groups always showed a group effect except when $Z_{1} / Z_{100}$ was entered in the regression in addition to height ${ }^{2} / Z_{1}$ and weight (Table 3 ).

The residuals of TBW and ECW using the general prediction equation were not significantly correlated with the mean value of predicted and measured TBW $(P=0.36)$ or ECW $(P=0.23)$ respectively but they were both significantly related to the ECW/TBW ratio (Fig. 2). The residuals of ECW were also correlated with the residuals of TBW $(r \mathbf{0 \cdot 3 5}$; $P=0.001)$ and with the ECW/height ratio $(r 0 \cdot 30, P=0.006)$. 

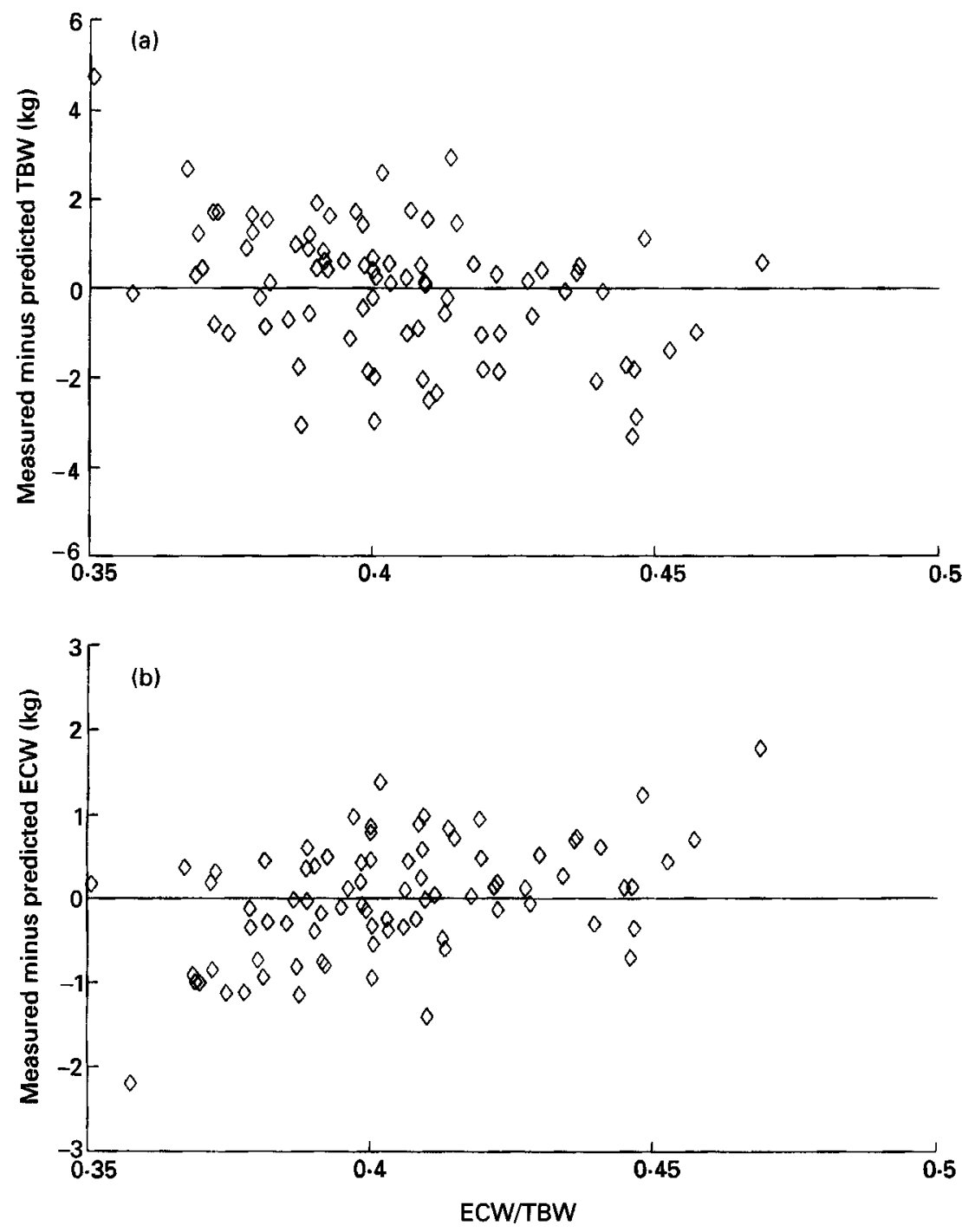

Fig. 2. Relationship between the extracellular water (ECW)/total body water (TBW) ratio and (a) measured - predicted TBW $(r-0.39, P<0.0003)$ and (b) measured - predicted ECW $(r 0.46, P<0.0005)$ with a general prediction equation developed from a combination of groups of subjects from Italy and The Netherlands.

\section{DISCUSSION}

The two groups of subjects were composed of healthy adult volunteers. The main differences in body build between the two groups were height and trunk height, which were greater in the Dutch subjects. Moreover, the Dutch women had higher trunk/height and lower arm/trunk and leg/trunk ratios than the Italian women.

The higher body weight of the Dutch subjects was due to a greater fat-free mass in men and a greater fat mass in women. These characteristics also explain the higher TBW and ECW content in the Dutch. However, the water content of both groups was in the normal range for sex and age (adult male: TBW 60\% weight, ECW 26\% weight; adult female: TBW $50 \%$ weight and ECW $20 \%$ weight; Task Group on Reference Man, 1975). 
As the ECW/TBW increases with the BMI (Moore et al. 1963) the higher ECW content in the Dutch females can be explained as a consequence of their higher BMI and fat mass. This may also explain their higher ECW/height value (Table 1).

TBW could be predicted from the impedance index at $100 \mathrm{kHz}$, weight, and sex, with a prediction error of about $1.5 \mathrm{~kg}$ (CV $4 \%$ ) using population-specific prediction formulas (Table 3). ECW could be predicted from the impedance index at $1 \mathrm{kHz}$, weight and sex, with a prediction error of about $0.6 \mathrm{~kg}$ (CV $4 \cdot 1-4.6 \%$ ). Theoretically, TBW and ECW predictions can be improved by using modelling techniques which provide extrapolated impedance values at zero frequency and infinite frequency. Such techniques are based on the Cole-Cole modelling (Cole \& Cole, 1941) or, alternatively, on the relationship between impedance and frequency (Deurenberg, 1995). However, studies conducted so far have shown that correlations between body-water compartments and impedance indices derived from extrapolated values are comparable to or lower than those obtained with indices from measured impedance values (van Marken Lichtenbelt et al. 1994; Deurenberg et al. 1995). Therefore predictive equations based on measured impedance values were used in the present study.

A comparison of the regression coefficients in population-specific equations showed that the relationship between multi-frequency impedance and body-water compartments in the two populations studied was similar for the prediction of TBW and differed only slightly for the prediction of ECW (Table 3). As a consequence, cross-validation was very successful for TBW but less so for ECW. However, it should be emphasized that the prediction errors were always within the acceptable range for this method (CV about $5 \%$ ).

The maximum mean error occurred in the application of the Italian ECW equation to the Dutch group (measured-predicted ECW $0.8 \mathrm{~kg}, \mathrm{CV}-4.9 \%, P<0.0005$ ). This is probably because the equation was developed in a group with lower ECW/TBW and ECW/height ratios and therefore tended to underestimate ECW. Residual analysis showed that the ECW residuals were mainly correlated with ECW/TBW (Fig 1) and ECW/height $(r 0.51, P<0.001)$.

As the value of body impedance is determined mainly by the values of the arm and leg (Baumgartner et al. 1989; Fuller \& Elia, 1989), whereas the majority of body water is located in the trunk, a positive relationship between the bias and the relative limb lengths might be expected. On the contrary, a slightly negative correlation was found. This may be due to the fact that the differences in relative limb lengths between the two groups were too small to demonstrate the expected relationship. Moreover, after correcting for ECW/TBW and $\mathrm{ECW} /$ height, the effect of differences in relative extremity lengths disappeared, showing that body-water distribution and water content per metre height are more important for explaining the bias in the prediction.

The bias in predicted ECW resulting from the use of a population-specific equation was greatly reduced if the ECW/height ratio was used in the equation. In the case of the Italian equation applied to Dutch subjects the bias became 0.3 (SD 0.4) instead of 0.8 (SD 0.8) $\mathrm{kg}$, a difference, however, which was still significant $(P<0.0005)$.

It would be useful to find a simple index of water distribution. Theoretically, $Z_{1} / Z_{100}$ is a measure of ECW/TBW (Jenin et al. 1975; Settle et al. 1980). In a previous study, Deurenberg \& Schouten (1992) did not find any correlation between these two variables before or after using a diuretic in a sample of twelve subjects. The authors explained this finding on the basis of the limited number of subjects and the small variability in the ECW/TBW ratio in the sample. However, the $Z_{1} / Z_{100}$ ratio increased after the diureticinduced water loss (mainly ECW), indicating that $Z_{1} / Z_{100}$ is indeed an index of ECW/TBW. In the present study, a significant correlation between ECW/TBW and $Z_{1} / Z_{100}$ was found in both groups separately $(r-0.34, P<0.05$ in Italians and $r-0.68$, $P<0.001$ in the Dutch) and in the combined groups $(n 83, r-0.30, P=0.006)$. The 
differences between the groups in predicted ECW disappeared when the $Z_{1} / Z_{100}$ ratio was entered in a prediction formula.

In conclusion, the water distribution between the extra- and intracellular compartments emerged in the present study as the major cause of error in the prediction of body water, and in particular of ECW from impedance measurements with population-specific equations. Moreover, body build, expressed as TBW/height and ECW/height, had an impact on the bias.

The authors wish to thank Frans J. M. Schouten for chemical analysis of the blood samples, and Jolanda ten Brinke, Diana van der Scheer, Claudia Trentani, Caterina Mamini and Katia Fasolo for their assistance in the measurements.

\section{REFERENCES}

Baumgartner, R. N., Chumlea, W. C. \& Roche, A. F. (1989). Estimation of body composition from bioelectrical impedance of body segments. American Journal of Clinical Nutrition 50, 221-226.

Cole, K. S. \& Cole, R. H. (1941). Dispersion and absorption in dielectrics. I. Alternating currents characteristics. Journal of Chemical Physics 9, 341-351.

Deurenberg, P. (1995). Multi-frequency impedance as a measure of body water compartments. In Body Composition Techniques and Assessment in Health and Disease, pp. 45-56 [P. S. W. Davies and T. J. Cole, editors]. Cambridge: Cambridge University Press.

Deurenberg, P. \& Schouten, F. J. M. (1992). Loss of body water and extra-cellular water assessed by multifrequency impedance. European Journal of Clinical Nutrition 46, 247-255.

Deurenberg, P., Tagliabue, A. \& Schouten, F. J. M. (1995). Multi-frequency impedance for the prediction of extracellular water and total body water. British Journal of Nutrition 73, 349-358.

Deurenberg, P., van der Kooy, K., Leenan, R. \& Schouten, F. J. M. (1989). Body impedance is largely dependent on the intra- and extra-cellular water distribution. European Journal of Clinical Nutrition 43, 845-853.

Durnin, J. V. G. A. \& Womersley, J. (1974). Body fat assessed from total body density and its estimation from skinfold thickness measurements in 481 men and women aged from 16 to 72 years. British Journal of Nutrition 32, 77-79.

Forbes, G. B. (1987). Human Body Composition. New York: Springer Verlag.

Fuller, N. J. \& Elia, M. (1989). Potential use of bioelectrical impedance of the whole body and of body segments for the assessment of body composition: comparison with densitometry and anthropometry. European Journal of Clinical Nutrition 43, 779-792.

Jenin, P., Lenoir, J., Roullet, C., Thomasset, A. L. \& Ducrot, H. (1975). Determination of body fluid compartments by electrical impedance measurements. Aviation, Space and Environmental Medicine 46, 152-155.

Kleinbaum, D. G. \& Kupper, L. L. (1978). Applied Regression Analysis and Other Multivariable Methods. North Scituate, MA: Duxbury Press.

Lukaski, H. C. \& Johnson, P. E. (1985). A simple, inexpensive method of determining total body water using a tracer dose of $\mathrm{D}_{2} \mathrm{O}$ and infrared absorption of biological fluids. American Journal of Clinical Nutrition 41, $363-370$.

Lukaski, H. C., Johnson, P. E., Bolonchuck, W. W. \& Lykken, G. E. (1985). Assessment of fat free mass using bio-electrical impedance measurements of the human body. American Journal of Clinical Nutrition 41, 810-817.

Miller, M. E. \& Cappon, C. J. (1984). Anion exchange chromatographic determination of bromide in serum. Clinical Chemistry 30, 781-783.

Moore, F. D., Olesen, K. H., McMurrey, J. D., Parker, H. V., Ball, M. R. \& Boyden, C. (1963). The body cell mass and its supporting environment. In Body Composition in Health and Disease, pp. 240-308. Philadelphia: W. B. Saunders.

Segal, K. R., Burastero, S., Chun, A., Coronel, P., Pierson, R. N. \& Wang, J. (1991). Estimation of extra-cellular water and total body water by multiple frequency bioelectrical impedance measurements. American Journal of Clinical Nutrition 54, 26-29.

Settle, R. G., Foster, K. R., Epstein, B. R. \& Mullen, J. L. (1980). Nutritional assessment: whole body impedance and body fluid compartments. Nutrition and Cancer 2, 72-80.

SPSS (1990). SPSS / PC V4.0 Manuals. Chicago, IL: SPSS Inc.

Task Group on Reference Man (1975). Report of the Task Group on Reference Man. ICRP Publication no. 23. Oxford: Pergamon Press.

van Marken Lichtenbelt, W. D., Westerterp, K. R., Wouters, L. \& Luijendijk, S. C. M. (1994). Validation of bioelectrical measurements as a method to estimate body water compartments. American Journal of Clinical Nutrition 60, 159-166. 